\title{
Bread-making performance of durum wheat as affected by sprouting
}

Gaetano Cardone, Silvia Grassi, Anna Scipioni, Alessandra Marti*

Department of Food, Environmental, and Nutritional Sciences (DeFENS). Università degli Studi di Milano, via G. Celoria 2, 20133 Milan, Italy

*Corresponding author:

E-mail address: alessandra.marti@unimi.it

address: via G. Celoria 2, 20133 Milan, Italy. 


\begin{abstract}
The effects of sprouting duration $(24 \mathrm{~h}, 38 \mathrm{~h}, 48 \mathrm{~h}$, and $62 \mathrm{~h})$ were assessed on durum wheat kernel characteristics (hardness, test weight), semolina chemical composition, pasting and gluten aggregation properties, and leavening and bread-making performance (bread volume and crumb porosity). Sprouting decreased both kernel hardness $(\sim 29 \%)$ and test weight $(\sim 19 \%)$. Starch gelatinization and retrogradation capability, as well as the gluten aggregation properties, decreased as sprouting duration increased. The $62 \mathrm{~h}$ sample showed the worst aggregation properties leading to a bread with the lowest specific volume $(2.69 \mathrm{~mL} / \mathrm{g})$. The best results in terms of bread specific volume $(3.08 \mathrm{~mL} / \mathrm{g})$ and crumb porosity distribution were obtained using semolina from sprouted wheat up to $38 \mathrm{~h}$. A multivariate approach by Principal Component Analysis and clustering confirmed the relationships between all the considered variables and allowed to assess three sprouting levels: 24-38 $\mathrm{h}$ with improved bread-making performance; $48 \mathrm{~h}$ with decreased overall quality; $62 \mathrm{~h}$ with the worst quality. In conclusion, the sprouting of durum wheat up to $38 \mathrm{~h}$ could improve its bread-making attitude.
\end{abstract}

Keywords: semolina; germination; pasting properties; gluten functionality; bread

Abbreviations: A0, radial area of the dough at the beginning of the leavening; A-am, $\alpha$-amylase activity; AgEn, Aggregation Energy; A_t, radial area of the dough at time t; BD, Breakdown index; CTRL: unsprouted durum wheat; DS, Damaged Starch; FV, Final Viscosity; Glu, D-glucose; GPE, GlutoPeak Equivalent; GPU, GlutoPeak Unit; Mal, Maltose; MT, Maximum Torque; PCA, Principal Component Analysis; PMT, Peak Maximum Time; Prot, Protein; PV, Peak Viscosity; SpV, Specific Volume; Suc, Sucrose; TS, Total Starch; V, bread volume. 


\section{Introduction}

Durum wheat (Triticum turgidum subsp. durum) is characterized by a peculiar hard and vitreous endosperm which influences its milling behavior, e.g., milling energy, yield and the starch damage (Turnbull \& Rahman, 2002). The strength and poor extensibility of its gluten network makes durum wheat the ideal raw material for pasta-making but unsuitable for baked-goods (Ammar, Kronstad, \& Morris, 2000). Despite the enhanced nutritional traits thanks to the carotenoids (Pasqualone, Caponio, \& Simeone, 2004), using durum wheat in bread-making results in low loaf volume and dense crumb structure (Sissons, 2008). However, dough extensibility and bread volume improved using sourdough fermentation, since the combination of acidity and hydrolytic activity of both lactic acid bacteria and yeasts positively affect durum wheat gluten functionality (Barber, Ortolá, Barber, \& Fernández, 1992). Considering the above, this study investigated the exploitation of the enzymatic pattern developed throughout sprouting to improve the bread-making performance of durum wheat. Although, an excessive accumulation of enzymes in wheat has always represented a negative event from a technological standpoint, recently it has been reported that sprouting improved the breadmaking performance of common wheat (Cardone, D'Incecco, Pagani, \& Marti, 2020a; Marti, Cardone, Nicolodi, Quaglia, \& Pagani, 2017; Marti, Cardone, Pagani, \& Casiraghi, 2018). In the case of durum wheat, the sprouting process have been recently investigated in relation to bioactive compounds (Jribi et al., 2019a) and functional properties (Jribi, Sahagùn, Debbabi, \& Gomez, 2019b) of wholemeal semolina. To the best of our knowledge, no study has focused yet on the relationship between sprouting and bread-making performance of durum wheat. Since the understanding of flour functionality is a key element in the production of cereal-based products, the aim of this study was to evaluate the effects of sprouting duration on durum wheat kernel characteristics, starch and gluten behavior, and their relationship with the bread characteristics also from a multivariate point of view, thus applying Principal Component Analysis and clustering.

\section{Materials and methods}




\subsection{Sample preparation}

Five aliquots (1 kg each) of durum wheat (Triticum durum Desf.), supplied by Molino Quaglia S.p.A. (Vighizzolo d'Este, Italy), were sprouted at $20^{\circ} \mathrm{C}$ for $24 \mathrm{~h}, 38 \mathrm{~h}, 48 \mathrm{~h}$ and $62 \mathrm{~h}$ and dried at $50^{\circ} \mathrm{C}$ for $9 \mathrm{~h}$, as previously reported by Grassi et al. (2018). Unsprouted durum wheat was used as control (CTRL). Unsprouted and sprouted samples were conditioned until they reached $165 \mathrm{~g} / \mathrm{kg}$ of water content and milled into refined semolina using a laboratory mill (RM1300, Erkaya, Ankara, Turkey), equipped with a $250 \mu \mathrm{m}$ sieve.

\subsection{Kernel hardness and test weight}

Kernel hardness was assessed by NIR (6500, Foss, Hilleroed, Denmark) following the AACC method 39-70.02 (AACCI 2011). Test weight was determined with a Grain Analysis Computer (2100b, DICKEY-john, Auburn, USA).

\subsection{Chemical composition and $\alpha$-amylase activity}

Total and damaged starch content were evaluated according to AACC methods (76-13.01 and 7631.01, respectively; AACCI 2001). Simple sugars were quantified by means of the Maltose/Sucrose/D-Glucose Assay kit commercialized by Megazyme (Wicklow, Ireland). Protein content was quantified by following the ISO method 20483:2006 (ISO, 2006). $\alpha$-amylase activity was determined according to the AACC method 22-02.01 (AACCI 2001). All the measurements were carried out in triplicate.

\subsection{Pasting properties}

Starch pasting properties were evaluated in duplicate by using the Rapid Viscoanalyzer® (4500, Perten Instrument, Stockholm, Sweden) according to the AACC method 76-21.01 (AACCI 2001) in presence of either water or silver nitrate $\left(\mathrm{AgNO}_{3} ; 0.001 \mathrm{~mol} / \mathrm{L}\right)$ as enzymatic inhibitor.

\subsection{Gluten aggregation properties}


Gluten aggregation kinetic was assessed in triplicate by using the GlutoPeak® (Brabender GmbH\&Co., Duisburg, Germany) device, according to Suárez-Estrella et al. (2020).

\subsection{Dough preparation and leavening properties}

Semolina was kneaded with fresh yeast (30 g/kg semolina; Carrefour, Milan, Italy) and salt (15 g/kg semolina; Candor ${ }^{\circledR}$, Com-Sal s.r.l., Pesaro, Italy) in an automatic mixer equipped with a spiral hook (KitchenAid 5KSM125EER, Whirlpool, St. Paul, USA) for 6 min, until a smooth and non-sticky dough was obtained. The amount of water used in the formulations has been added on the basis on preliminary farinographic tests. Specifically, $645 \mathrm{~g} / \mathrm{kg}$ of water was added to CTRL and $24 \mathrm{~h}$ sample, $605 \mathrm{~g} / \mathrm{kg}$ of water for $38 \mathrm{~h}$ and $48 \mathrm{~h}$ samples and, finally, $585 \mathrm{~g} / \mathrm{kg}$ of water for $62 \mathrm{~h}$ sample. Three portions ( $5 \mathrm{~g}$ each) of the resulted doughs were molded in a spherical shape and then placed in three Petri dishes, and subjected to leavening at $30^{\circ} \mathrm{C}$. The Petri dishes were scanned at 300 dpi with a flatbed scanner (Epson Perfection 550 Photo, Seiko-Epson, Suwa, Japan) at the beginning of the test, and after $15 \mathrm{~min}, 30 \mathrm{~min}, 45 \mathrm{~min}, 60 \mathrm{~min}, 90 \mathrm{~min}, 120 \mathrm{~min}$ and $180 \mathrm{~min}$. The radial increase of the dough area $(\mathrm{mm} 2)$ was determined by image analysis using the Image Pro Plus software v. 6.0 (Media Cybernetics, Inc., Rockville, USA) and it was used to determine the relative increase of dough surface (A_t/A_t0), through the ratio between the area at time $t\left(A \_t\right)$ and the area of the dough at the beginning of the test (A_t0), according to (Caramanico et al., 2018).

\subsection{Micro-baking test}

Dough samples were obtained as reported in the previous paragraph. Samples were shaped, left to rise $\left(90 \mathrm{~min}\right.$ at $30^{\circ} \mathrm{C}$ ) and baked $\left(20 \mathrm{~min}\right.$ at $200^{\circ} \mathrm{C}$ ) as reported by Cardone et al. (2020a). The obtained loaves were characterized $2 \mathrm{~h}$ after baking. One baking test was performed for each sample and two loaves were obtained.

\subsection{Bread properties}

Each loaf was characterized for specific volume $(\mathrm{SpV})$ through the ratio between the bread volume, evaluated by seed replacement method (AACC 10-05.01; AACCI, 2001) and the bread weight. 
Crumb porosity was assessed on three slices from each loaf as described by Marti et al. (2017) with some modifications about pore dimensional classes (i.e. $<0.09 \mathrm{~mm} 2 ; 0.10-0.99 \mathrm{~mm} 2 ; 1.00-2.99 \mathrm{~mm} 2$; 3.00-9.99 $\mathrm{mm} 2 ;>10.00 \mathrm{~mm} 2$ ). Crumb yellowness was evaluated on three points of three central slices from each loaf by means of digital colorimeter (Digital Color Meter, Apple Inc., Cupertino, USA).

\subsection{Statistical analysis}

Data were elaborated by a paired t-Test $(\alpha=0.05)$ through the software StatPlus:mac (v.7.3.31, (Analystsoft, Inc., Walnut, USA), to compare differences between mean for unsprouted (CTRL) and each sprouted sample for different duration for each parameter. Moreover, a type of homoscedastic or heteroscedastic t-Test was selected according to whether the variance of the pair of the tested samples was equal or different, respectively. In order to provide the precision of the measurements, for the parameters in which the variance of the samples was comparable, the pooled SD (i.e. the square-root of a pooled variance estimator) was calculated. Data were also explored by Principal Component Analysis (PCA) after data mean centering by means of Matlab software (v. 2016a, Mathworks, Inc., Natick, USA). Samples grouping was confirmed by K-Nearest Neighbor cluster analysis (PLS toolbox, v. 8.5, Eigenvector Research, Inc., Manson, USA).

\section{Results}

\subsection{Kernel characteristics}

The sprouting process caused a significant decrease in both kernel hardness (from 112 to 78 after 24 h of sprouting) and test weight (from $80 \mathrm{~kg} / \mathrm{hL}$ to $69 \mathrm{~kg} / \mathrm{hL}$ after $24 \mathrm{~h}$ of sprouting).

\subsection{Chemical composition and $\alpha$-amylase activity}

Sprouting did not affect the starch content, instead the damaged starch fraction statistically $(\mathrm{p}=9.01 * 10-5)$ increased after $38 \mathrm{~h}$ of sprouting (Table 1$)$. As the damaged starch increased also simple sugars statistically increased; in particular, maltose increased $(p=4.47 * 10-4)$ after $24 \mathrm{~h}$, instead sucrose $\left(\mathrm{p}=3.44 * 10_{-2}\right)$ after $38 \mathrm{~h}$, and glucose $\left(\mathrm{p}=4.61 * 10_{-2}\right)$ after $48 \mathrm{~h}$ of sprouting (Table 1$) . \alpha-$ 
amylase activity statistically $(\mathrm{p}=1.60 * 10-4)$ increased by about 260 folds, already after $24 \mathrm{~h}$ of sprouting (Table 1).

Sprouting duration did not strongly affect the protein content of semolina, which decreased by about $6 \%$ (Table 1).

\subsection{Pasting properties}

Regardless the sprouting duration, in presence of water, sprouted samples showed low viscosity values $\left(<0.1 \mathrm{~Pa}^{*} \mathrm{~s}\right)$, in both heating and cooling stages (data not shown). Inhibiting the amylase activity with a solution of silver nitrate $\left(\mathrm{AgNO}_{3} ; 0.001 \mathrm{~mol} / \mathrm{L}\right)$ all samples showed a higher viscosity, indicating that the pasting and gelation properties of sprouted samples were not drastically affected by sprouting (Figure 1a). Specifically, the peak viscosity $\left(1.866 \pm 0.008 \mathrm{~Pa}^{*}\right.$ s for CTRL, $1.58 \pm 0.02$, $1.34 \pm 0.04,1.1755 \pm 0.0007$ and $1.156 \pm 0.008 \mathrm{~Pa}^{*} \mathrm{~s}$ for $24 \mathrm{~h}, 38 \mathrm{~h}, 48 \mathrm{~h}$ and $62 \mathrm{~h}$, respectively) and the breakdown index (i.e. resistance of the gel to mechanical stress) $\left(0.44 \pm 0.01 \mathrm{~Pa}^{*} \mathrm{~s}\right.$ for CTRL, $0.39 \pm 0.03,0.33 \pm 0.04,0.275 \pm 0.006$ and $0.36 \pm 0.04 \mathrm{~Pa}^{*} \mathrm{~s}$ for $24 \mathrm{~h}, 38 \mathrm{~h}, 48 \mathrm{~h}$ and $62 \mathrm{~h}$, respectively) significantly decreased after $24 \mathrm{~h}(\mathrm{p}=3.46 * 10-2)$ and $48 \mathrm{~h}(\mathrm{p}=3.38 * 10-2)$ of sprouting, respectively. Moreover, the final viscosity and the setback index (i.e. the tendency of starch to retrograde) statistically $(\mathrm{p}=4.34 * 10-2)$ decreased as sprouting duration increased, starting from $24 \mathrm{~h}$ of sprouting (2.92 $\pm 0.04 \mathrm{~Pa}^{*}$ s for CTRL, 2.471 $\pm 0.008,2.163 \pm 0.002,1.95 \pm 0.01$ and $1.71 \pm 0.08 \mathrm{~Pa}^{*} \mathrm{~s}$ for $24 \mathrm{~h}, 38 \mathrm{~h}$, $48 \mathrm{~h}$ and $62 \mathrm{~h}$, respectively).

\subsection{Gluten aggregation properties}

As regards changes in gluten aggregation kinetics (Figure 1b), sprouting led to a significant $(\mathrm{p}=1.21 * 10-3)$ increase in the peak maximum time starting from $38 \mathrm{~h}$ of sprouting $(60 \pm 2 \mathrm{~s}$ for CTRL, $62 \pm 3,83 \pm 2,77 \pm 2$ and $98 \pm 6 \mathrm{~s}$ for $24 \mathrm{~h}, 38 \mathrm{~h}, 48 \mathrm{~h}$ and $62 \mathrm{~h}$, respectively), and a significant decrease in both maximum torque $(\mathrm{p}=3.34 * 10-4)(47.0 \pm 0.8$ GPU for CTRL, 31.8 $\pm 0.9,26.4 \pm 0.1,24.2 \pm 0.9$ and 20.5 \pm 0.7 GPU for 24 h, 38 h, 48 h and 62 h, respectively) and aggregation energy ( $p=4.48 * 10-2)$ (i.e. energy required for gluten aggregation; $1239 \pm 47$ GPE for CTRL, 887 $\pm 15,758 \pm 9,694 \pm 21$ and 
$592 \pm 15$ GPE for 24 h, 38 h, $48 \mathrm{~h}$ and 62 h, respectively), already after $24 \mathrm{~h}$ and $38 \mathrm{~h}$ of sprouting, respectively.

\subsection{Dough leavening properties}

Dough leavening properties were evaluated by monitoring changes in radial area. CTRL reached the maximum development in 45 min (A_t45/A_t0=2.3) and no longer increased up to 120 min of leavening; after that, it decreased (A_t180/A_t0=2.0) (Figure 2). In contrast, the radial area of sprouted wheat dough constantly increased until the end of the test period (A_t180/A_t0=2.7) (Figure 2). The fastest area expansion was observed after $24 \mathrm{~h}$ and $36 \mathrm{~h}$ of sprouting, subsequent to leavening for $15 \mathrm{~min}$.

\subsection{Bread-making properties}

Using sprouted wheat did not lead to a drastic worsening of bread properties, in terms of volume, not even after $62 \mathrm{~h}$ of sprouting $(178 \pm 4,173 \pm 4,180 \pm 1,180 \pm 1$ and $178 \pm 4 \mathrm{~mL}$ for CTRL, $24 \mathrm{~h}, 38 \mathrm{~h}, 48$ $\mathrm{h}$ and $62 \mathrm{~h}$, respectively). Samples from $38 \mathrm{~h}$ sprouted wheat showed the best bread-making performances, in terms of specific volume (Figure 3). Instead, $62 \mathrm{~h}$ sprouted sample showed the worst crumb structure, that appeared sticky and irregular (Figure 3). As regards crumb yellowness, loaves from sprouted wheat showed a more intense yellowness (Figure 3).

No significant differences $(\mathrm{p}>0.05)$ were observed among the samples in terms of number of cells (data not shown). Unlike that, differences were observed in cell area (Table 2). Specifically, CTRL bread showed a crumb characterized by about $70 \%$ of small cells $(<1 \mathrm{~mm} 2)$, instead this pore class represented about $50 \%$ of the total in loaves from sprouted wheat. Moreover, large pores (> $10 \mathrm{~mm} 2)$ were found only in bread from sprouted wheat whose area accounted for the $10 \%$ of the total for 24 $\mathrm{h}$ bread, instead about $5 \%$ for $38 \mathrm{~h}$ and $48 \mathrm{~h}$ loaves.

\subsection{PCA and cluster analysis}

PCA results showed sample distribution according to chemical composition, $\alpha$-amylase activity, dough leavening properties and bread-making properties. The scores plot defined by the first PCs 
described almost the $83 \%$ of the data variability $(\mathrm{PC} 1=55.87 \%$; $\mathrm{PC} 2=27.11 \%)$ and showed a clear separation of CTRL samples from sprouted samples (Figure 4a). Indeed, CTRL samples assumed highly positive PC1 and PC2 values, being in the I quadrant of the plot. $24 \mathrm{~h}$ sprouted sample is located in the IV quarter, assuming the lowest PC2 value; $38 \mathrm{~h}$ sprouted samples was well separated in the III quarter; finally, $48 \mathrm{~h}$ and $62 \mathrm{~h}$ samples were grouped in the II quarter. Scores $v s$ time representation (Figure 4b) enabled to highlight that PC1 described an unique process as the scores values decreased with time progress, whereas PC2 trajectory was characterized by a sudden decrease in the first $24 \mathrm{~h}$ followed by an increment of the scores after $38 \mathrm{~h}$ and a consecutive decrement in the last sampling time. In order to uncover the variables responsible for sample grouping the loadings plot was presented (Figure 4c). Most of the chemical indexes and $\alpha$-amylase drove the separation of CTRL sample from sprouted samples along PC1, together with gluten aggregation properties; whereas leavening properties and bread characteristics resulted relevant in the discrimination among samples subjected to different sprouting duration ( $24 \mathrm{~h}, 38 \mathrm{~h}, 48 \mathrm{~h}$ and $62 \mathrm{~h})$.

The explorative data analysis showed a sample distribution according to the sprouting duration (Figure 4c), envisioning the possibility of defining sprouting classes according to the considered parameter. However, the confirmation of sample grouping according to sprouting duration needed more solid bases, thus a cluster analysis was performed. The cluster analysis based on K-Nearest Neighbor algorithm identified four clusters based on the whole results collected. From the dendrogram (Figure 4d), the first cluster, i.e. the group that differed the most from the others, was the one formed by CTRL which resulted highly different (distance $=7$ ) from the sprouted samples, no matter the sprouting duration. By reducing the distance to 5, the analysis individuated three sprouting levels: a cluster consisting of $24 \mathrm{~h}$ and $38 \mathrm{~h}$ sprouted samples and other two separated clusters for 48 $\mathrm{h}$ and $62 \mathrm{~h}$ sprouted samples.

\section{Discussion}


Compared to common wheat, durum wheat is characterized by high kernel hardness, high gluten tenacity and intensive yellowness - due to its high carotenoid content. All these characteristics are used to evaluate the grain quality on the market. As regards the kernel characteristics, sprouting process led to a significant decrease in hardness (Figure S1), with the greatest changes occurring at $48 \mathrm{~h}$ sprouting duration (Figure S1). The decrease in kernel hardness might positively affect the milling behavior. Indeed, hard kernels, such as durum wheat, require more energy to be milled than both soft and hard kernels (Różyło et al., 2003). Specifically, the decrease in kernel hardness might be attributed to the decrease in starch-protein matrix density in the endosperm. This hypothesis has been confirmed by the decrease in test weight (i.e. index related to the kernel density; Figure S1) due to the high $\alpha$-amylase activity associated with sprouting (Table 1). The effect of enzymatic activity on decreasing the endosperm density as a consequence of sprouting has been recently shown in sprouted common wheat (Cardone, D’Incecco, Casiraghi, \& Marti, 2020b). Moreover, the decrease in kernel hardness and test weight were in line with previous study carried out on sprouted common wheat (Miś \& Grundas, 2002; Różyło, Laskowski, \& Grundas, 2003). However, both the indices seemed not to be affected by the sprouting duration (Figure S1).

In addition to milling energy, hardness also affects the milling yield and the damaged starch content of flours (Turnbull \& Rahman, 2002). In this study, the milling yield did not appear to be affected by the sprouting duration within $48 \mathrm{~h}$, ranging from $49 \mathrm{~g} / 100 \mathrm{~g}$ for CTRL, to 48, 46, 47 and $38 \mathrm{~g} / 100 \mathrm{~g}$ for $24 \mathrm{~h}, 38 \mathrm{~h}, 48 \mathrm{~h}$ and $62 \mathrm{~h}$, respectively (data not shown). The low yield ratio obtained could be due to the use of a laboratory mill that allowed to extract mainly the innermost regions of the endosperm, at the expenses of the yield. The decrease in milling yield might be related to the decrease in test weight (Figure S1), with evidence at prolonged sprouting durations. Indeed, after $62 \mathrm{~h}$ the rootlet was quite evident (Figure S1), suggesting an intense hydrolysis of the storage macromolecules, as confirmed by the increased $\alpha$-amylase activity. It is generally recognized that the sprouting process is considered concluded when the rootlet reached the kernel length, in order to avoid strongly negative effects on the kernel properties and flour functionality (Marti, Cardone, \& Pagani, 2020). During 
sprouting, high levels of hydrolytic enzymes - specifically $\alpha$-amylases - are released and create some holes on the surface of the starch granules (Cardone et al., 2020a; Faltermaier, Zarnkow, Becker, Gastl, \& Arendt, 2015), making them more accessible to a further enzymatic action. Thus, the level of damaged starch (which is defined as the amount of starch readily accessible to $\alpha$-amylase) might provide information about the intensity of the sprouting process. In general, high damaged starch content adversely affects the dough handling (e.g. greater water absorption and dough stickiness) and the bread characteristics (e.g. lower development in volume and darker crust color) (Sapirstein, David, Preston, \& Dexter, 2007). Under the condition applied in this study, the damaged starch content increased as the sprouting duration increased too (Table 1), as an effect of the increased $\alpha$ amylase activity (Table 1), rather than exclusively as mechanical damage of the starch granules during milling. These findings were confirmed by the multivariate exploration by PCA, indeed damaged starch and $\alpha$-amylase activity were close to each other and located in the II quarter of the loadings plot (Figure 4c) affecting the separation of samples sprouted $48 \mathrm{~h}$ and $62 \mathrm{~h}$ from lower germination exposure (24 h and $38 \mathrm{~h}$ ) and CTRL (Figure 4a), thus driving the separation of these samples along PC1 according to sprouting duration (Figure 4b)

Sprouting resulted in lower pasting and gelation properties (Figure 1a), because of the lower gelatinization and retrogradation ability of the smaller starch polymers accumulated in sprouted samples than CTRL. These changes were in line with other studies on sprouted durum (Jribi et al., 2019b) and common (Cardone et al., 2020a; Grassi et al., 2018) wheat and also remarked by the PCA loadings plot (Figure 4c), in which the pasting and gelation indexes calculated from the analysis performed in presence of water or silver nitrate assumed positive PC1 scores, thus separating the CTRL from the sprouted samples (Figure 4a). Furthermore, the lower ability to retrograde of the sprouted samples might have led to obtain a fresh bread with a softer crumb, compared to the CTRL one, as shown in common wheat (Cardone et al., 2020a,b) and quinoa-enriched bread (Suárez-Estrella et al., 2020). 
As regards the proteins, the decrease (Table 1) might be attributable to their hydrolysis into soluble peptides due to the proteolytic activity (Mbithi-Mwikya, Ooghe, Van Camp, Ngundi, \& Huyghebaert, 2000). On the other hand, it is reported that changes in protein content less than $10 \%$ indicates that the sprouting process did not significantly affect the protein content of grains (Lemmens et al., 2019). Similar changes are reported in previous studies on sprouted durum (Jribi et al., 2019a) and common (Cardone et al., 2020a; Grassi et al., 2018; Koehler, Hartmann, Wieser, \& Rychlik, 2007; Marti et al., 2017) wheat.

Moving to gluten properties, the sprouting duration negatively affected the aggregation properties of the gluten-forming proteins (Figure $1 \mathrm{~b}$ ), in terms of peak maximum time (increased by $\sim 63 \%$ after $62 \mathrm{~h}$ of sprouting), maximum torque (decreased by $\sim 56 \%$ after $62 \mathrm{~h}$ of sprouting) and aggregation energy (decreased by $\sim 52 \%$ after $62 \mathrm{~h}$ of sprouting), suggesting a weakening of the gluten network (Grassi et al., 2018; Marti, Augst, Cox, \& Koehler, 2015a), as a consequence of the proteolytic activity. In general, flour with good bread-making performance are characterized by a faster aggregation (i.e., low peak maximum time) and higher maximum torque compared to those with poor bread-making attitude (Quayson, Atwell, Morris, \& Marti, 2016). Actually, the aggregation properties of the gluten-forming proteins resulted the ones most affecting the separation between CTRL and the highly sprouted samples along the PC1 of the PCA scores plot (Figure 4a), being the peak maximum time highly negative and maximum torque and aggregation energy highly positive. A possible explanation of the maximum torque and the peak maximum time shifts is that sprouting induced changes in the profile of gluten proteins (i.e. gliadin and glutenin fractions) (Koehler et al., 2007). Indeed, Marti et al. (2015b) found a positive correlation between maximum torque and gliadin content and between energy and glutenin with high molecular weight. In particular, it is already reported that sprouting caused a significant degradation of glutenins, already after $48 \mathrm{~h}$ of sprouting, instead longer duration was required for degrading gliadins, about 102 h (Koehler et al., 2007). Although the sprouted samples showed a different gluten aggregation profiles that would suggest gluten weakening, they were still able to aggregate and form a gluten network with good performance 
in bread-making (Figure 1b), confirming previous studies on common wheat (Cardone et al., 2020a;

Marti et al., 2018). The only exception was the $62 \mathrm{~h}$ sample that lost its ability to form gluten (Figure 1b), likely due to the stronger intensity of the sprouting process (Figure S1; Table 1).

In comparison with common wheat, durum wheat is characterized by a very stiff and not very extensible gluten, making it suitable for the pasta-making but unsuitable for leavened baked-goods (Ammar et al. 2000). Indeed, the resulting bread will be characterized by a high density and a hard texture (Sissons, 2008). The interest in durum wheat bread lies in the fact that this raw material is richer in carotenoids (i.e. antioxidant compounds) compared to common wheat. Generally, to overcome the negative technological properties (i.e., low volume and high crumb density) of durum wheat bread, sourdough fermentation is used as leavening agent. Indeed, the low $\mathrm{pH}$ and the enzymatic activities of lactic bacteria and yeasts enhanced bread-making performance, in terms of bread volume (Barber et al., 1992; Pagani, Lucisano \& Mariotti, 2014). In this context, the increased enzymatic activity developed during sprouting process might represent a good strategy to improve the bread-making attitude of durum wheat.

Thanks to the correlations between dough tenacity and strength and maximum torque and aggregation energy (Marti et al., 2015b; Rakita, Dokić, Dapčević Hadnađev, Hadnađev, \& Torbica, 2018), it is possible to hypothesize that sprouting could represent a good way to decrease dough tenacity and consequently improve its bread-making performance. Despite the gluten weakening (Figure 1b), the dough from sprouted durum wheat was able to withstand the leavening stresses, expanding itself without collapsing (Figure 2). The increased $\mathrm{CO}_{2}$ production during leavening - thanks to the increased amount of fermentable sugars by yeasts, resulting from the $\alpha$-amylase activity (Table 1) increased loaf specific volume, mainly for the $38 \mathrm{~h}$ sample (Figure 3 and Figure $4 \mathrm{a}$ ). Similar results are reported for common wheat (Cardone et al., 2020a; Marti et al., 2018). The worsening of crumb structure in bread from $62 \mathrm{~h}$ sprouted wheat (Figure 3) agreed with the excessive gluten weakening (Figure 1b). Indeed, the poor gluten aggregation properties and its gas retention capacity resulted in the lowest specific volume (Figure 3). As regards the pore distribution, large pores (>10 mm2) were 
found only in bread from sprouted wheat, probably due to the coalescence of the gas cells, favored by $\alpha$-amylase activity (Lagrain, Leman, Goesaert, $\&$ Delcour, 2008). In addition, bread from sprouted wheat resulted in a higher crumb yellowness (Figure 3), following a similar trend of the yellow index of semolina (from $19 \pm 1$ for CTRL to $25.4 \pm 0.8$ after $62 \mathrm{~h}$; data not shown). Yang et al. (2001) report that the $\beta$-carotene content increased upon sprouting and the color intensity of the carotenoid extract increased as the sprouting duration increased too. Although this aspect needs to be further investigated, finding suggests that sprouting process might have a positive effect on the carotenoid content in bread from sprouted durum wheat.

All the considered chemical composition, $\alpha$-amylase activity, dough leavening properties and breadmaking properties do not act separately but are interconnected and correlated. Thus, the multivariate approach led us to confirm the relationships between all the considered variables and to define which of them contributed most in the sample distribution, i.e. in assessing the sprouting influence in the final product, as Grassi et al. (2018) speculate. Indeed, the dendrogram obtained by the cluster analysis (Figure 4d) confirmed that samples sprouted up to $38 \mathrm{~h}$ had similar and improved breadmaking performance. The two distinct clusters for $48 \mathrm{~h}$ and $62 \mathrm{~h}$ sprouted samples (Figure $4 \mathrm{~d}$ ) indicated a progressive and significant decrease of the overall quality.

\section{Conclusions}

Changes induced by sprouting strongly depended on the process duration. Specifically, sprouting under controlled conditions (i.e., up to $48 \mathrm{~h}$ ) did not strongly compromise the functional properties of starch (i.e., gelatinization and retrogradation phenomena). As regards proteins, despite the sprouting process weakened the gluten network, gluten proteins were still able to aggregate and retain gas during leavening, resulting in bread with improved volume. Specifically, the best bread-making performance were achieved using durum wheat that was sprouted for $38 \mathrm{~h}$.

Overall results suggest that sprouting carried out under controlled conditions could improve the bread-making attitude of durum wheat and produce a more attractive product (i.e. improved bread 
volume and crumb porosity) for the consumer and with high carotenoid content compared to common bread. However, the effects of sprouting process on gliadin and glutenin fractions need to be studied in depth, as well as the potential application of the process on various durum wheat varieties.

Acknowledgments. The authors wish to thank M.A. Pagani (formerly Università degli Studi di

Milano, Italy) for the critical discussion during the manuscript preparation.

\section{Declarations of interest: none}

\section{References}

AACC Approved Methods of Analysis, 11th Ed. Cereals \& Grains Association, St. Paul, MN, USA. Ammar, K., Kronstad, W. E., \& Morris, C. F. (2000). Breadmaking quality of selected durum wheat genotypes and its relationship with high molecular weight glutenin subunits allelic variation and gluten protein polymeric composition. Cereal Chemistry, 77, 230-236.

Barber, B., Ortolá, C., Barber, S., \& Fernández, F. (1992). III. Effects of sour dough and addition of acids on bread characteristics. Zeitschrift Für Lebensmittel-Untersuchung Und - For - Schung, $194,442-449$.

Caramanico, R., Marti, A., Vaccino, P., Bottega, G., Cappa, C., Lucisano, M., \& Pagani, M. A. (2018). Rheological properties and baking performance of new waxy lines: Strengths and weaknesses. LWT - Food Science and Technology, 88, 159-164.

Cardone, G., D’Incecco, P., Casiraghi, M. C., \& Marti, A. (2020b). Exploiting milling by-products in bread-making: the case of sprouted wheat. Foods, 9, 260.

Cardone, G., D’Incecco, P., Pagani, M. A., \& Marti, A. (2020a). Sprouting improves the breadmaking performance of whole wheat flour (Triticum aestivum L.). Journal of the Science of Food and Agriculture, 1000, 2453-2459.

Faltermaier, A., Zarnkow, M., Becker, T., Gastl, M., \& Arendt, E. K. (2015). Common wheat (Triticum aestivum L.): evaluating microstructural changes during the malting process by using 
confocal laser scanning microscopy and scanning electron microscopy. European Food Research and Technology, 241, 239-252.

Grassi, S., Cardone, G., Bigagnoli, D., \& Marti, A. (2018). Monitoring the sprouting process of wheat by non-conventional approaches. Journal of Cereal Science, 83, 180-187.

ISO 20483. (2006). Cereals and pulses-Determination of the nitrogen content and calculation of the crude protein content-Kjeldahl method. International Organization for Standardization, Geneva, Switzerland.

Jribi, S., Molnar, H., Adanyi, N., Marzougui, S., Naar, Z. \& Debbabi, H. (2019b). Effect of sprouting temperature on durum wheat (Triticum Durum) sprouts nutritional properties and bioactive compounds. International Journal of Innovative Approaches in Agricultural Research, 3, 87-95.

Jribi, S., Sahagùn, M., Debbabi, H., \& Gomez, M. (2019a). Evolution of functional, thermal and pasting properties of sprouted whole durum wheat flour with sprouting time. International Journal of Food Science \& Technology, 54, 2718-2724.

Koehler, P., Hartmann, G., Wieser, H., \& Rychlik, M. (2007). Changes of folates, dietary fiber, and proteins in wheat as affected by germination. Journal of Agricultural and Food Chemistry, 55, $4678-4683$.

Lagrain, B., Leman, P., Goesaert, H., \& Delcour, J. A. (2008). Impact of thermostable amylases during bread making on wheat bread crumb structure and texture. Food Research International, $41,819-827$.

Lemmens, E., Moroni, A. V., Pagand, J., Heirbaut, P., Ritala, A., Karlen, Y., ..., \& Delcour, J. A. (2019). Impact of cereal seed sprouting on its nutritional and technological properties: a critical review. Comprehensive Reviews in Food Science and Food Safety, 18, 305-328.

Marti, A., Augst, E., Cox, S., \& Koehler, P. (2015a). Correlations between gluten aggregation properties defined by the GlutoPeak test and content of quality-related protein fractions of winter wheat flour. Journal of Cereal Science, 66, 89-95. 
Marti, A., Cardone, G., Nicolodi, A., Quaglia, L., \& Pagani, M. A. (2017). Sprouted wheat as an alternative to conventional flour improvers in bread-making. LWT - Food Science and Technology, 80, 230-236.

Marti, A., Cardone, G, \& Pagani, M. A. (2020). Sprouted cereal grains and products. In Innovative Processing Technologies for Healthy Grains. Submitted

Marti, A., Cardone, G., Pagani, M. A., \& Casiraghi, M. C. (2018). Flour from sprouted wheat as a new ingredient in bread-making. LWT - Food Science and Technology, 89, 237-243.

Marti, A., Ulrici, A., Foca, G., Quaglia, L., \& Pagani, M. A. (2015b). Characterization of common wheat flours (Triticum aestivum L.) through multivariate analysis of conventional rheological parameters and gluten peak test indices. LWT - Food Science and Technology, 64, 95-103.

Mbithi-Mwikya, S., Ooghe, W., Van Camp, J., Ngundi, D., \& Huyghebaert, A. (2000). Amino acid profiles after sprouting, autoclaving, and lactic acid fermentation of finger millet (Eleusine coracan) and kidney beans (Phaseolus vulgaris L.). Journal of Agricultural and Food Chemistry, 48, 3081-3085.

Miś, A., \& Grundas, S. (2002). Wheat grain hardness modified by the laboratory sprouting test. International Agrophysics, 16, 283-288.

Pagani, M.A., Lucisano, M., \& Mariotti, M. (2014). Italian bakery products. In W. Zhou, Y. H. Hui, I. De Leyn, M. A. Pagani, C. M. Rosell, J. D. Selman, \& N. Therdthai (Eds.), Bakery Products Science and Technology (pp. 685-721). Hoboken: John Wiley \& Sons, Ltd.

Pasqualone, A., Caponio, F., \& Simeone, R. (2004). Quality evaluation of re-milled durum wheat semolinas used for bread-making in Southern Italy. European Food Research and Technology, 219, 630-634.

Quayson, E. T., Atwell, W., Morris, C. F., \& Marti, A. (2016). Empirical rheology and pasting properties of soft-textured durum wheat (Triticum turgidum ssp. durum) and hard-textured common wheat (T. aestivum). Journal of Cereal Science, 69, 252-258. 
Rakita, S., Dokić, L., Dapčević Hadnađev, T., Hadnađev, M., \& Torbica, A. (2018). Predicting rheological behavior and baking quality of wheat flour using a GlutoPeak test. Journal of Texture Studies, 49, 339-347.

Różyło, R., Laskowski, J., \& Grundas, S. (2003). Study of how protein content in wheat grain relates to hardness index and grinding energy. Acta Agrophysica, 2, 173-178.

Sapirstein, H. D., David, P., Preston, K. R., \& Dexter, J. E. (2007). Durum wheat breadmaking quality: effects of gluten strength, protein composition, semolina particle size and fermentation time. Journal of Cereal Science, 45, 150-161.

Sissons, M. (2008). Role of durum wheat composition on the quality of pasta and bread. Food, 2, 75-90.

Suárez-Estrella, D., Cardone, G., Buratti, S., Pagani, M. A., \& Marti, A. (2020). Sprouting as a preprocessing for producing quinoa-enriched bread. Submitted

Yang, T. K., Basu, B., \& Ooraikul, F. (2001). Studies on germination conditions and antioxidant contents of wheat grain. International Journal of Food Sciences and Nutrition, 52, 319-330. 


\section{Figure captions}

Figure 1. Rapid Viscoanalyzer (in presence of silver nitrate - AgNO3; $0.001 \mathrm{~mol} / \mathrm{L}$ ) (a) and GlutoPeak (b) profiles of semolina from unsprouted (CTRL) and sprouted durum wheat. CTRL: solid line; 24 h: dotted line; 38 h: short dash line; 48 h: dash-dot-dot line; 62 h: long dash line. 24 h, 38 h, 48 h, 62 h: sprouting duration; CTRL: unsprouted durum wheat; GPU: GlutoPeak Units.

Figure 2. Increasing the radial area (A_t/A_t0) of the dough during leavening. CTRL: dash-line; 24 h: black square; 38 h: grey circle; 48 h: black triangle; 62 h: grey diamond.

Asterisk indicates a significant difference between CTRL and each sample from sprouted wheat (paired t-Test; $\alpha=0.05 ; \mathrm{n}=3$ ). n.s.: not significant differences. $24 \mathrm{~h}, 38 \mathrm{~h}, 48 \mathrm{~h}, 62 \mathrm{~h}$ : sprouting duration; A_t0, radial area of the dough at the beginning of the leavening; A_t, radial area of the dough at time t; CTRL: unsprouted durum wheat.

Figure 3. Pictures of the bread loaves, crumb yellowness and specific volume ( $\mathrm{SpV})$ of bread prepared from semolina from unsprouted (CTRL) and sprouted durum wheat. Asterisk indicates a significant difference between CTRL and each bread sample from sprouted wheat (paired t-Test; $\alpha=0.05 ; n=5$ for crumb yellowness; $\mathrm{n}=2$ for specific volume). Scale bar is $1 \mathrm{~cm} .24 \mathrm{~h}, 38 \mathrm{~h}, 48 \mathrm{~h}, 62 \mathrm{~h}$ : sprouting duration; CTRL: unsprouted durum wheat.

Figure 4. Multivariate data analysis on data collected for chemical composition, $\alpha$-amylase activity, dough leavening properties and bread-making properties: scores plot for Principal Component Analysis (a), scores vs sprouting duration plot (b), loadings plot (c), dendrogram for cluster analysis by K-Nearest Neighbor (d)

A-am, $\alpha$-amylase activity; TS, Total Starch; DS, Damaged Starch; Mal, Maltose; Suc, Sucrose; Glu, D-glucose; Prot, Protein. Pasting properties: PV, Peak Viscosity; BD, Breakdown index; FV, Final Viscosity. Gluten aggregation properties: PMT, Peak Maximum Time; MT, Maximum Torque; AgEn, Aggregation Energy. Leavening properties: relative increase of dough surface at $15 \min$ 
(A_t15), $30 \mathrm{~min}($ A_t30), $45 \mathrm{~min}($ A_t45), $60 \mathrm{~min}$ (A_t60), $90 \mathrm{~min}$ (A_t90), $120 \mathrm{~min}$ (A_t120) and 180 min (A_t180). Bread characteristics: SpV, Specific Volume; V, Bread Volume.

Figure S1. Kernel hardness and test weight of durum wheat kernels during sprouting process, from $24 \mathrm{~h}$ to $62 \mathrm{~h}$ 

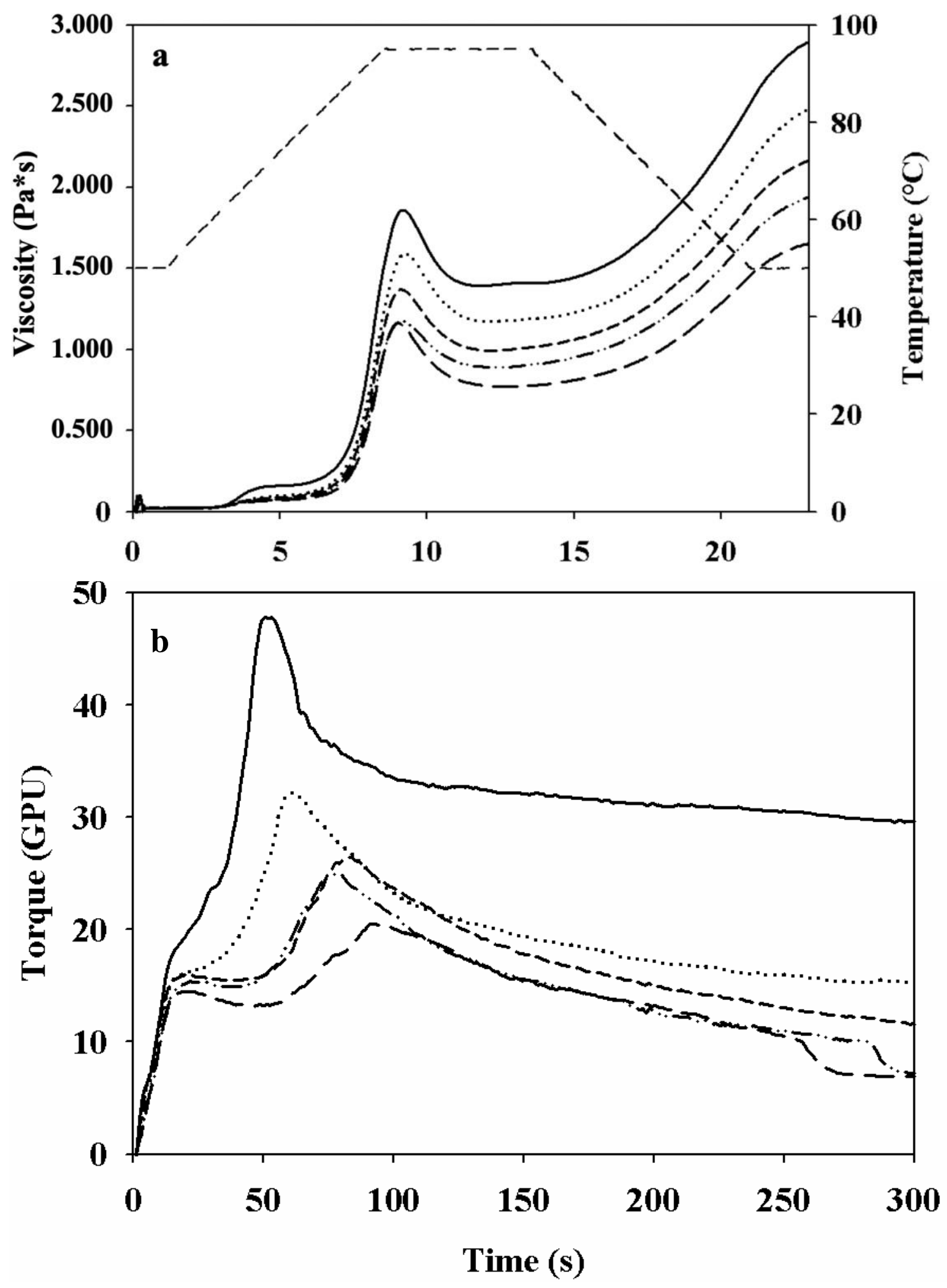

Figure 1. 


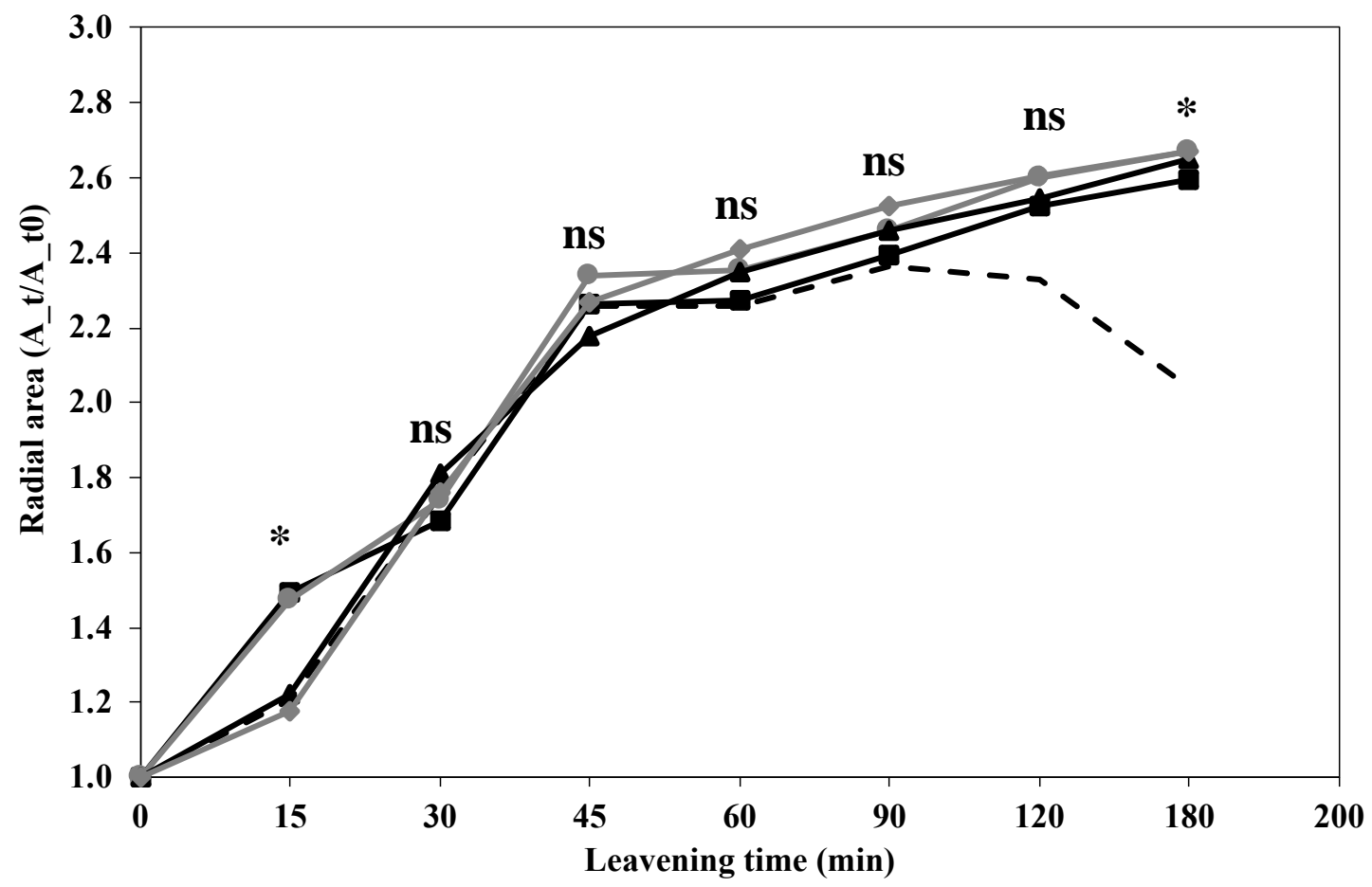

Figure 2. 


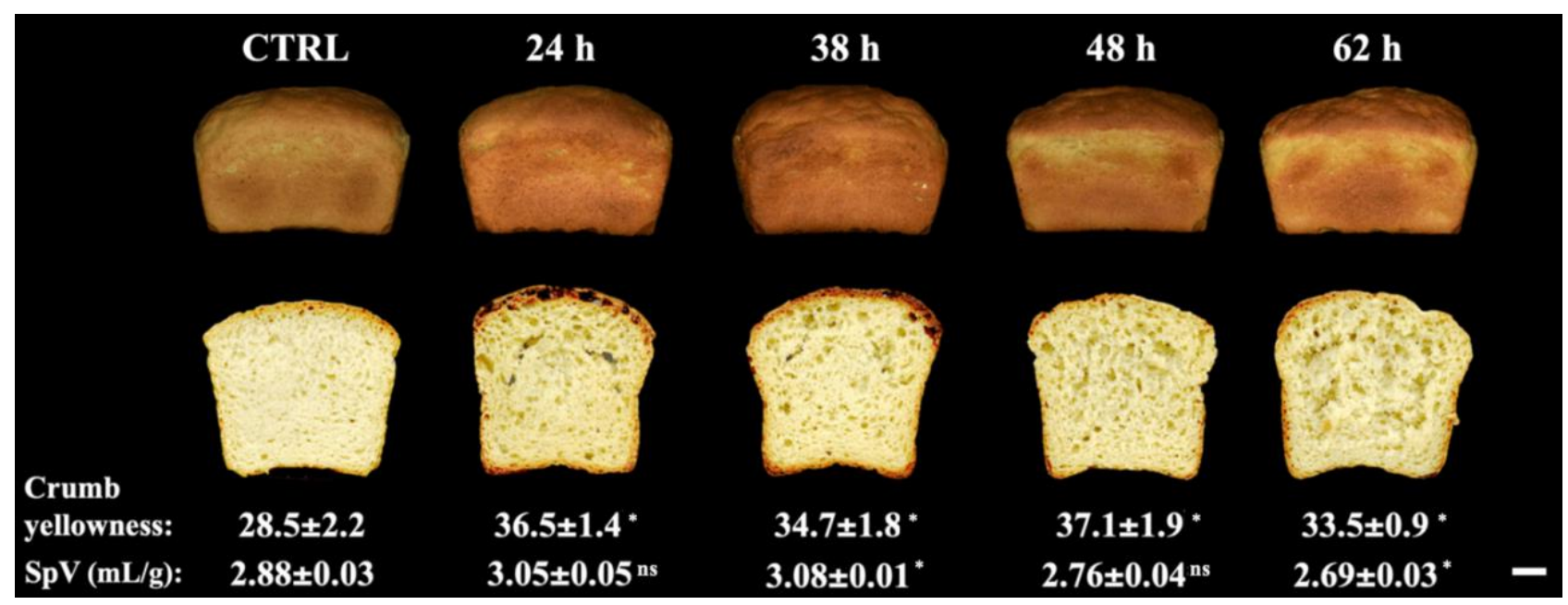

Figure 3. 

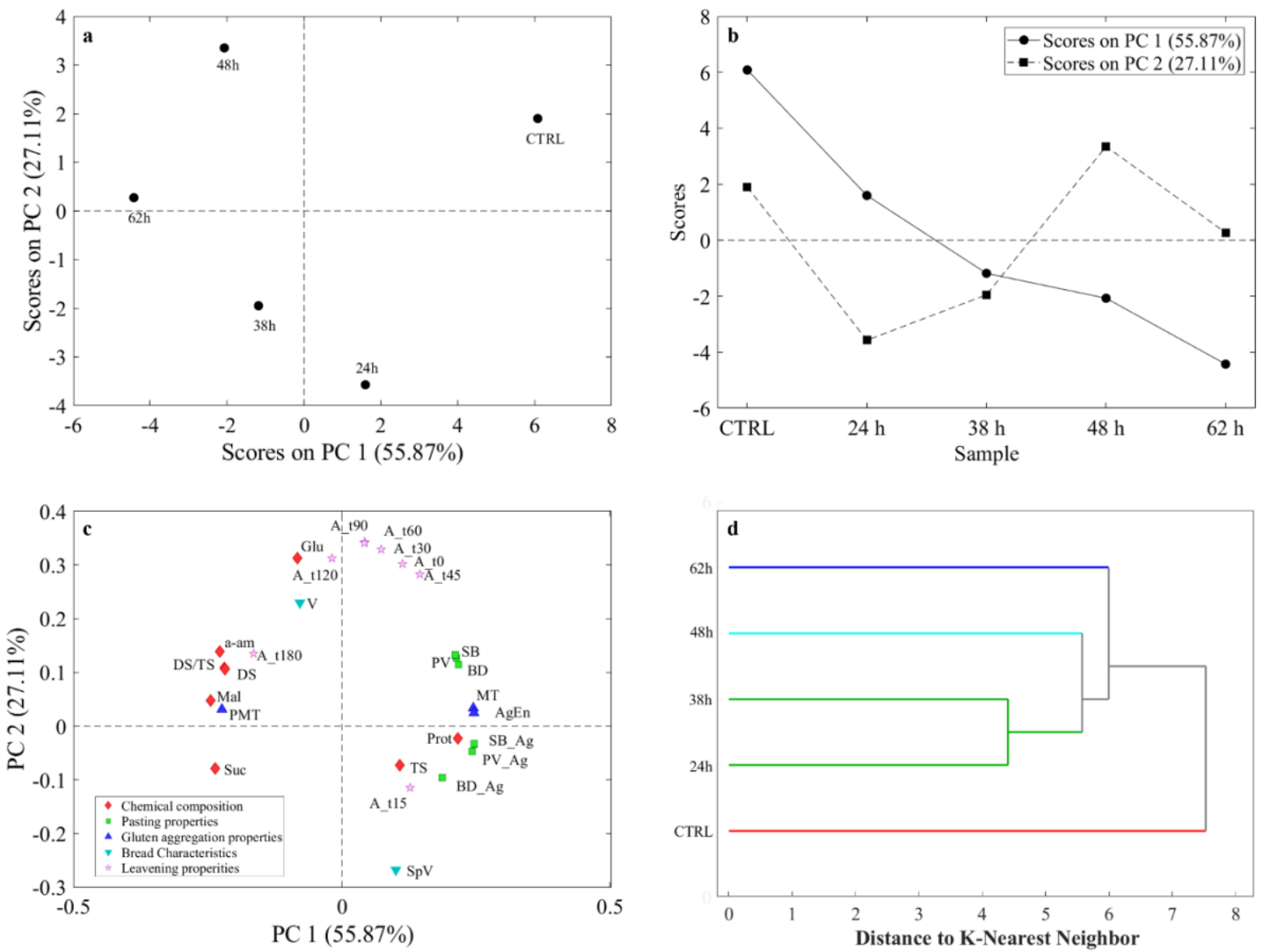

Figure 4. 
Table 1. Chemical characteristics (starch, simple sugar and protein contents) and $\alpha$-amylase activity of semolina from unsprouted (CTRL) and sprouted durum wheat at different sprouting duration $(24 \mathrm{~h}, 38 \mathrm{~h}, 48 \mathrm{~h}$ and $62 \mathrm{~h})$.

\begin{tabular}{ccccccc}
\hline & $\mathbf{C T R L}$ & $\mathbf{2 4} \mathbf{~ h}$ & $\mathbf{3 8 ~ h}$ & $\mathbf{4 8 ~ h}$ & $\mathbf{6 2} \mathbf{~ h}$ & Pooled SD \\
\hline Total starch & 71 & $71 \mathrm{~ns}$ & $72 \mathrm{~ns}$ & $71 \mathrm{~ns}$ & $69 \mathrm{~ns}$ & 1 \\
Damaged starch & 10.3 & $9.7 *$ & $13.2 *$ & $13.4 *$ & $15.9 *$ & 0.3 \\
Maltose & 0.3 & $2.1 *$ & $4.7 *$ & $5.4 *$ & $6.6^{*}$ & 0.4 \\
Sucrose & 1.5 & $1.9 \mathrm{~ns}$ & $2.0 *$ & $2.0 *$ & $2.1 *$ & 0.2 \\
D-glucose & 0.20 & $0.16 \mathrm{~ns}$ & $0.3 \mathrm{~ns}$ & $0.41 *$ & $0.42 *$ & 0.2 \\
Protein & 14.18 & $14.11 \mathrm{~ns}$ & $13.80 \mathrm{~ns}$ & $13.88^{*}$ & $13.32 *$ & 0.03 \\
$\alpha$-amylase activity & $0.089 \pm 0.004$ & $3.8 \pm 0.3 *$ & $9.9 \pm 0.5 *$ & $21.6 \pm 0.9 *$ & $24.3 \pm 0.2^{*}$ & -
\end{tabular}

Chemical data are expressed as $\mathrm{g} / 100 \mathrm{~g}$ sample (dry basis). Damaged starch is expressed as $\mathrm{g} / 100 \mathrm{~g}$ of total starch (dry basis). $\alpha$-amylase activity is expressed as Ceralpha Units/g flour (dry basis). Asterisk indicates a significant difference between CTRL and each sprouted sample (paired t-Test; $\alpha=0.05$; $n=3$ ). CTRL: unsprouted durum wheat; 24 h, 38 h, 48 h, 62 h: sprouting duration; ns: not significant difference. 
Table 2. Area occupied by each pore dimensional class of the bread crumb (\%).

\begin{tabular}{cccccc}
\hline $\begin{array}{c}\text { Dimensional } \\
\text { classes }(\mathbf{m m} \mathbf{m})\end{array}$ & $\mathbf{C T R L}$ & $\mathbf{2 4} \mathbf{h}$ & $\mathbf{3 8} \mathbf{h}$ & $\mathbf{4 8} \mathbf{h}$ & Pooled SD \\
\hline$<0.09$ & 8.9 & $8.7 \mathrm{~ns}$ & $9.3 \mathrm{~ns}$ & $7.8 \mathrm{~ns}$ & 0.7 \\
$0.10-0.99$ & 59 & $42 *$ & $47 *$ & $43 *$ & 2 \\
$1.00-2.99$ & 26 & $25 \mathrm{~ns}$ & $23 \mathrm{~ns}$ & $28 \mathrm{~ns}$ & 4 \\
$3.00-9.99$ & 8 & $14 \mathrm{~ns}$ & $14 \mathrm{~ns}$ & $17 \mathrm{~ns}$ & 3 \\
$>10.00$ & - & 7 & 10 & 4 & 2 \\
\hline
\end{tabular}

Asterisk indicates a significant difference between CTRL and each sprouted sample (paired t-Test; $\alpha=0.05 ; \mathrm{n}=3$ ). CTRL: unsprouted durum wheat; 24 h, 38 h, 48

h: sprouting duration; ns: not significant difference. 


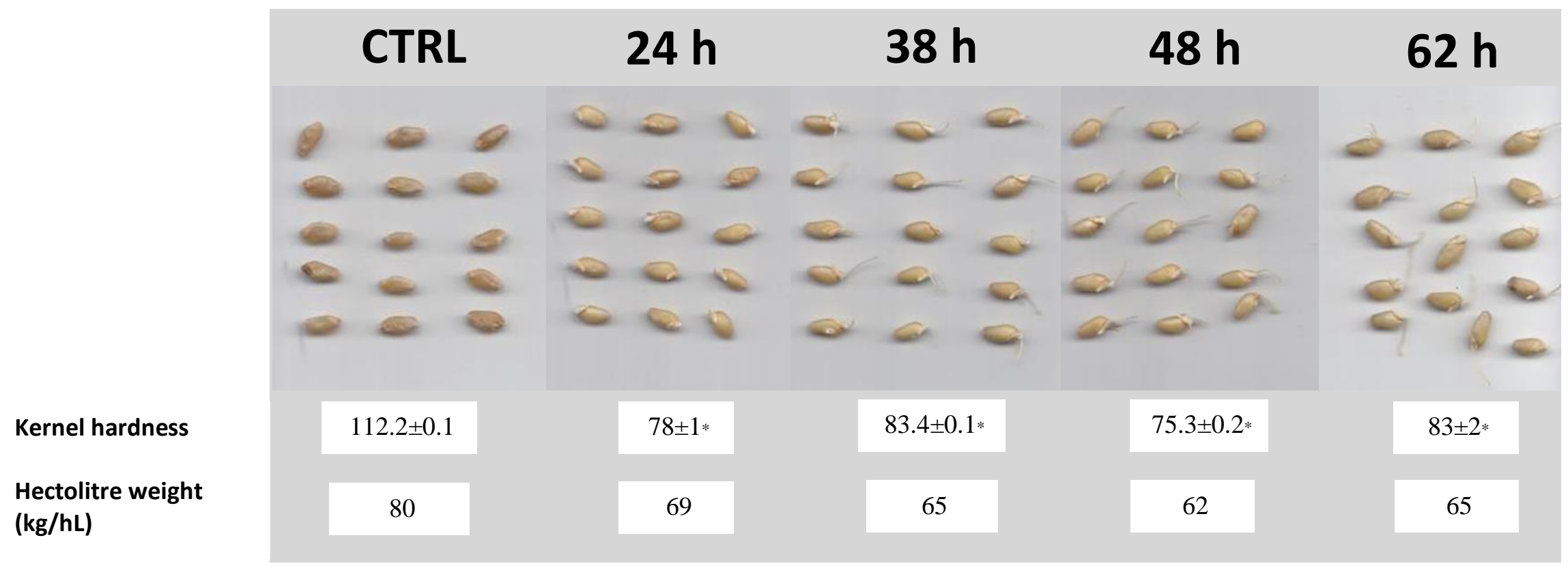

Figure S1. Kernel hardness and hectolitre weight of durum wheat kernels during sprouting process, from $24 \mathrm{~h}$ to $62 \mathrm{~h}$.

Asterisk indicates a significant difference between CTRL and each bread sample from sprouted wheat (paired t-Test; $\alpha=0.05 ; n=2$ ). 


\section{Highlights:}

- Sprouting of durum wheat decreased the kernel hardness and hectolitre weight

- Starch and gluten properties were not strongly affected up to $48 \mathrm{~h}$ of sprouting

- Sprouting process improved dough leavening attitude of durum wheat

- Using sprouted durum wheat up to $38 \mathrm{~h}$ addressed to the highest bread specific volume 